\title{
MEMBANGUN INTERAKSI DAN KOMUNIKASI INTERPERSONAL YANG EFEKTIF : KOMPETENSI HUMAS BERKOMUNIKASI DI FACEBOOK
}

Oleh:

\author{
F A Z I L \\ Mahasiswa Pascasarjana Ilmu Komunikasi Universitas Andalas Padang
}

\begin{abstract}
ABSTRACK
Retrieved from kominfo.go.id, the Director of Information Services of International Directorate General of Public Information and Communication, Selamatta Sembiring, said that $95 \%$ of internet users accesses social networking sites. The most accessible social networking sites are Facebook and Twitter. This research uses descriptive qualitative approach by using methods which are data collection, interview, and documentation. The interaction in interpersonal communication on Facebook tends to be similar to the daily interpersonal communication. Both of them have similar steps of daily interpersonal communication process as proposed by Devito (1997:233) which are contact, involvement, familiarity, destruction, and termination. The next development is that the connectivity among Facebook users is no longer based on known people who live far away. Facebook expands the reach of connectedness based on specific needs of humans. As shown on the early development of Facebook, that connection is expanded on university students. It can be seen from the specific need of university students that is the need of educational information. The existence of new media, especially Facebook, cannot be underestimated by public relations. It can be a chance to optimize its role and its function internally and externally or publicly. The existence of new media repositions public affairs function which tends to be closed and one-way communication to be open and two-way communication. This new situation requires public relations to have the appropriate interaction competence in the public as well as effective interpersonal communication on social media, especially Facebook.
\end{abstract}

Keywords : interpersonal communication, public information and communication, facebook

\section{PENDAHULUAN}

Facebook, sebuah layanan jejaring sosial yang diluncurkan pada bulan Februari 2004 ini, dimiliki dan dioperasikan oleh Facebook, Inc. Ide pembuat layanan sini adalah seorang mahasiswa Universitas Harvard, Mark Zuckerberg. Tujuan pembuatnya mulanya sederhana, yaitu sebagai media penghubung dan mengeratkan kembali dengan teman-teman sekamar asramanya semasa di kampus yang telah berpencar-pencar setamat studi. Perlahan keanggotaan Facebook berkembang ke seluruh mahasiswa 
Harvard, lalu diperluas kepada perguruan tinggi lain di Boston Ivy League, dan Universitas Stanford.Dalam perkembangannya, Facebook membuka diri kepada mahasiswa universitas lain sebelum dibuka untuk siswa sekolah menengah atas, dan akhirnya untuk setiap orang yang berusia minimal tiga belas tahun (www.id.wikipedia.org).

Kini siapa saja yang mempunyai akses internet dan perangkat elektronik yang berusia minimal tiga belas tahun bisa mendaftarkan akun Facebook. Pengguna harus mendaftar sebelum dapat menggunakan situs ini. Setelah itu, pengguna dapat membuat profil pribadi, menambahkan pengguna lain sebagai teman, dan bertukar pesan, termasuk pemberitahuan otomatis ketika mereka memperbarui profilnya. Selain itu, pengguna dapat bergabung dengan grup dengan ketertarikan dan minat yang sama, berdasarkan tempat kerja, sekolah atau perguruan tinggi, atau ciri khas lainnya. Pengguna juga bisa mengelompokkan teman-teman mereka ke dalam daftar seperti "Rekan Kerja" atau "Teman Dekat" (id.wikipedia.org).

Pengguna Facebook di dunia lebih dari 1,27 milliar (app.thefacesoffacebook.com). Di Indonesia yang berpenduduk mencapai 250 juta jiwa, pengguna Facebook menurut data dari Webershandwick, perusahaan public relations dan pemberi layanan jasa komunikasi, untuk wilayah Indonesia ada sekitar 65 juta pengguna Facebook aktif. Sebanyak 33 juta pengguna aktif per harinya, 55 juta pengguna aktif yang memakai perangkat mobile dalam pengaksesannya per bulan dan sekitar 28 juta pengguna aktif yang memakai perangkat mobile per harinya (sindonews.com).

Dikutip

dari

laman kominfo.go.id, Direktur Pelayanan Informasi Internasional Ditjen Informasi dan Komunikasi Publik (IKP), Selamatta Sembiring mengatakan, 95 persen pengguna internet mengakes situs jejaring sosial. Ada pun situs jejaring sosial yang paling banyak diakses adalah Facebook dan Twitter. Indonesia menempati peringkat empat pengguna Facebook terbesar di dunia setelah USA, Brazil, dan India. Data dari situs SocialBakers, pengguna Facebook di Indonesia didominasi yang berumur antara 18-24 tahun di posisi pertama dan 25-34 tahun di urutan kedua.Sedangkan dari jenis kelaminnya, pengguna Facebook di Indonesia didominasi oleh pria dengan persentase sebesar 59 persen, sisanya adalah wanita (www.merdeka.com).

Meskipun sempat dikabarkan pengguna Facebook menurun, tren pengguna Facebook masih menunjukkan kecenderungan naik.Kecenderungan naik ditenggarai karena seiring peningkatan perangkat mobile yang mudah akses internet dan berdampak pada pengalaman ber-Facebook yang bisa di mana dan kapan saja.Menurut pihak Facebook, jumlah pengguna Facebook di Indonesia per hari asal Indonesia mencapai angka 33 juta orang.Pengguna yang mengakses Facebook via mobile setiap harinya mencapai angka 28 juta. Sementara, jumlah pengguna aktif bulanan Facebook via situs web di Indonesia 
mencapai 65 juta orang. Pengguna yang secara aktif membuka Facebook via mobile tercatat sebanyak 55 juta orang (www.tekno.kompas.com). Ada beberapa alasan masyarakat Indonesia tertarik menggunakan Facebook. Menurut Julian Sukmana Putra, seorang konsultan sebuah perusahaan multinasional IT di Indonesia (www.quora.com/Why-isFacebook-so-populer-in-

indonesia), disebutkan bahwa:

1. Alasan pertama adalah budaya. "Indonesia adalah Facebook dalam kehidupan nyata. Budaya Indonesia didasarkan pada berbagi, komunikasi dan solidaritas". Facebook memfasilitasi masyarakat Indonesia untuk berhubungan dengan keluarga, teman dan orang-orang penting dalam hidup mereka dengan mudah.

2. Selain pengaruh budaya, kecenderungan masyarakat Indonesia untuk mengikuti tren. Hal ini berlaku tidak hanya untuk Facebook, tetapi jejering sosial lainnya yang telah mengalami pertumbuhan yang signifikan di Indonesia.

3. Karena semakin banyak orang bisa terhubung melalui Facebook, mereka seolah-olah tidak bisa menolak untuk bergabung karena sebagian besar teman-teman mereka berada di sana.

Berdasarkan permasalahan ini, tulisan ini bermaksud mendeskripsikan bagaimana interaksi dan komunikasi interpersonal yang efektif melalui Facebook.Dari tulisan ini menjadi bekal untuk meningkatkan kompetensi humas dan mampu menerapkannya saat situasi tertentu mengharuskan berinteraksi dan berkomunikasi langsung dengan individu-individu di Facebook.

\section{METODE PENELITIAN}

Penelitian ini merupakan penelitian crossectional, karena penelitian ini hanya dilakukan dalam satu waktu. Penelitian ini hanya digunakan dalam waktu yang tertentu, dan tidak akan dilakukan penelitian lain di waktu yang berbeda untuk diperbandingkan. Adapun metode yang digunakan dalam penelitian ini adalah data didapat melalui data sekunder diperoleh melalui studi kepustakaan yang dilakukan dengan mengumpulkan literatur atau buku yang berhubungan dengan penelitian, serta dokumendokumen lainnya. Untuk mendukung studi lapangan peneliti melakukan wawancara mendalam dengan narasumber yang kompeten di bidangnya masing-masing

\section{HASIL PENEITIAN DAN PEMBAHASAN}

\section{Proses Interaksi Komunikasi Interpersonal Di Facebook}

Interaksi dalam komunikasi interpersonal di Facebook cenderung sama dengan interpersonal dalam komunikasi interpersonal sehari-hari. Persamaan keduanya bisa digambarkan dari tahapan-tahapan berlangsungnya proses komunikasi interpersonal sehari-hari seperti yang diungkapkan Devito (1997:233) yaitu kontak, keterlibatan, 
keakraban, perusakan, dan pemutusan.

Terjadinya proses komunikasi interpersonal di Facebook karena kontak antarmanusia. Kontak ini ditandai jejak-jejak material maya berupa foto, kata-kata, video, dan lain-lain di Facebook. Aktivitas jejak-jejak material maya tersebut menunjukkan proses komunikasi berlangsung di media Facebook. Tanpa keterhubungan (kontak) antarmanusia, Facebook hanya menjadi media kosong sebagai tempat sementara disinggahi penggunatanpa interaksi antarmanusia. Adanya keterhubungan ini antarpengguna Facebook merupakan persamaan dengan tahap pertama komunikasi interpersonal sehari-hari, yaitu kontak.

Keterhubungan ini adalah esensi penciptaan Facebook. Mark Zuckerberg menciptakan Facebook untuk menghubungkan manusia (baca: teman-teman) yang dipisahkan oleh jarak tempat. Keterhubungan ini membuat manusia-manusia yang berjauhan tempat menjadi kembali merasa dekat.

Akan tetapi, keterhubungan ini tidak serta membuat manusiamanusia yang berjauhan menjadi dekat. Kedekatan memerlukan keterlibatan (interaksi) dalam keterhubungan tersebut. Karena itu, dalam Facebook, terdapat fasilitasfasilitas yang disediakan agar keterhubungan antarmanusia tersebut ada keterlibatan, yaitu dengan fasilitas pemajangan foto, video, percakapan (chat), notes (catatan), dan wall (dinding), dan lain-lain.
Interaksi saat memanfaatkan fasilitas-fasilitas Facebook tersebut mengarahkan pada perasaan dekat (akrab) di antara teman, kerabat, atau keluarga yang berjauhan. Keterlibatan antar pengguna Facebook merupakan persamaan tahap kedua dengan komunikasi interpersonal sehari-hari.Dengan keterlibatan ini menciptakan perasaan dekat dan akrab sehingga hubungan komunikasi antarpengguna memasuki tahapan ketiga, yaitu keakraban.

Perkembangan selanjutnya, keterhubungan antarpengguna Facebook tidak lagi berdasarkan orang-orang yang dikenal yang berjauhan. Facebook meluaskan jangkauan keterhubungan berdasarkan kebutuhan-kebutuhan spesifik manusia. Seperti yang tertunjukkan pada awal perkembangan Facebook, keterhubungan itu diluaskan pada antar mahasiswa kampus. Keterhubungan ini bisa dilihat berdasarkan kebutuhan spesifik mahasiswa yaitu kebutuhan akan informasi dalam pendidikan.

Semula keterhubungan akan kesamaan kebutuhan akan informasi ini bergeser pada kebutuhankebutuhan lain antarpengguna Facebook sesuai beragammya latar belakang pengguna. Sebagai manusia yang multidimensi (biologis, psikologis, sosial, religius, dan dinamis) maka kebutuhan-kebutuhan spesifik manusia dengan mediasi Facebook menjadi lebih kompleks. Secara garis besar kebutuhan manusia dengan keterhubungan antarpengguna Facebook memenuhi dua kebutuhan primer manusia, yaitu (1) kebutuhan untuk 
memiliki (the need to belong) dan (2) kebutuhan unjuk diri (the need for self-presentation.

Kebutuhan ini diurai Sheldon (via Mahmud, 2013) dalam motifmotif pengguna Facebook, yaitu: 1) menjaga hubungan (keakraban), 2) menghabiskan waktu, 3) partisipatif dalam komunitas maya, 4) menghibur diri, 5) unjuk kehebatan diri, 6) saling-mengenal antara teman, 7) pengungkapan diri; dan 8) mendapat informasi.

Keterhubungan antarmanusia yang luas untuk memenuhi kebutuhan yang sudah beragam dan spesifik menyebabkan keterlibatan komunikasi interpersonal seharisehari maupun Facebook menjadi berkurang intensitasnya. Kurangnya keterlibatan dalam komunikasi interpersonal (baik sehari-hari maupun Facebook) menyebabkan berkurangnya keakraban. Tahapan hubungan dalam komunikasi interpersonal mulai mengarah pada tahap keempat dan kelima, yaitu pengrusakan hingga pemutusan.

\section{Komunikasi Interpersonal yang Efektif Di Facebook}

Menurut Jalaluddin Rachmat dalam bukunya Psikologi Komunikasi (1996:119) mengatakan komunikasi yang efektif ditandai dengan hubungan interpersonal yang baik (keakraban).Kegagalan komunikasi sekunder terjadi, bila isi pesan kita pahami, tetapi hubungan di antara pelaku komunikasi menjadi rusak. Komunikasi interpersonal yang efektif meliputi banyak unsur, tetapi hubungan interpersonal (keakraban) barangkali yang paling penting. Setiap kali kita melakukan komunikasi, kita bukan hanya sekadar menyampaikan isi pesan; kita juga menentukan kadar hubungan interpersonal- bukan hanya menentukan "content" tetapi juga "relationship" (keakraban).

Dalam pendekatan humanistik, ada lima kualitas umum yang perlu dipertimbangkan atau dipenuhi humas untuk mencapai efektifitas (keterlibatan dan keakraban) komunikasi interpersonal yaitu: 1) Keterbukaan (Openess); 2. Empati (Empathy); 3) Dukungan (Supportiveness); 4) Rasa positif (positiveness); 5) Kesetaraan atau kesamaan (Equality).Ketika salah satu kualitas umum ini tidak terpenuhi, efektivitas (keakraban dan keterlibatan) dalam komunikasi interpersonal sudah berkurang hingga terjadi pergeseran.

\section{Keterbukaan}

Dalam

komunikasi interpersonal, humas harus ada kesediaan membuka diri. Membuka diri dalam artian berbicara tidak berbohong dan apa adanya. Jika berbohong, menunjukkan informasi disembunyikan atas perasaan dan pikirannya.Membuka diri dalam arti juga pendengar benar-benar memberi tanggapan atas stimulus dengan jujur atas perasaan dan pikiran, bukan dibuat-buat demi alasan menyenangkan teman bicara. Ungkapkan penolakan dengan santun jika tidak tertarik atau tidak mengerti dengan apa yang dibicarakan.

Membuka diri berarti pula apa yang kita pikir dan rasa adalah memang "milik" kita bukan berdasarkan pendapat orang atau perasaan orang. Dengan menyatakan kepemilikan ini, maka ada tanggung jawab atas apa yang dirasa dan dipikir sehingga penerimaan 
menangkap itu adalah sesuai dengan dirinya bukan memalsukan dirinya. Jadi, membuka diri adalah mengungkap diri sesuai yang dipikir dan dirasa dengan rasa tanggung jawab, jujur dan santun.

\section{Empati}

Setelah keterbukaan diri dilakukan humas, selanjutnya untuk komunikasi interpersoal yang efektif juga diperlukan empati. Berempati adalah merasakan sesuatu seperti orang yang mengalaminya-berada di kapal yang sama dan merasakan perasaan yang sama dengan cara yang sama. Orang empatik mampu memahami motivasi dan pengalaman orang lain, perasaan dan sikap mereka, serta harapan dan keinginan mereka untuk masa datang. Pengertian yang empatik ini akan membuat seseorang lebih mampu menyesuaikan komunikasinya. Ketidakmampuan seseorang untuk "mengetahui" apa yang sedang dialami orang lain pada suatu saat tertentu, dari sudut pandang orang lain itu, melalui kacamata orang lain itu membuat ketidakefektisan dalam proses komunikasi.

Empati yang akurat melibatkan baik kepekaan terhadap perasaan yang ada maupun fasilitas verbal untuk mengkomunikasikan empati baik secara verbal maupun nonverbal. Secara nonverbal, kita dapat mengkomunikasikan empati dengan memperlihatkan:

keterlibatan aktif dengan orang itu melalui ekspresi wajah, nada suara dan gerak-gerik yang sesuai; (2) konsentrasi terpusat meliputi kontak mata, postur tubuh yang penuh perhatian, dan kedekatan fisik; serta (3) sentuhan atau belaian yang sepantasnya. Dalam Facebook, empati ini hanya bisa disikapi dalam bentuk tulisan dan gambar (video call).

Empati ini didapat jika di antara pelaku komunikasi ada keterbukaan diri.Selain itu empati didapati jika kita perhatian dalam komunikasi sehingga memahami dan punya interaksi. Setelah mendapat empati, menunjukkan empati melalui ekspresi dan gerak-gerik yang sesuai situasi.

Empati tetapi tidak ditunjukkan sesuai dengan situasi, menyebabkan salah pemaknaaan antar pelaku komunikasi.Misalnya "sedih", berempati tetapi ditertawakan.Atau salah satu pelaku komunikasi mengharapkan empati kita tetapi kita tidak memberi sikap mendukung atau tidak peduli, maka terjadilah ketidakefektifan dalam komunikasi interpersonal.

\section{Sikap Mendukung}

Komunikasi interpersonal yang efektif adalah hubungan di mana terdapat sikap mendukung.Komunikasi

interpersonal yang terbuka dan empatik tidak dapat berlangsung dalam suasana yang tidak mendukung.Kita memperlihatkan sikap mendukung dengan bersikap (1) deskriptif bukan evaluatif, (2) spontan, bukan strategik dan (3) profesional bukan sangat yakin.

Saat berkomunikasi dalam hubungan interpersonal yang penuh penilaian maka pelaku komunikasi akan cenderung defensif (menutup diri, membela diri). Karena itu perlu dihilangkan sikap menilai dan diganti dengan cara menggambarkan (deskriptif) seseorang apa adanya tanpa unsur penilaian. 
Suasana mendukung akan terbangun bila ada spontanitas dalam berbicara. Orang yang spontan dalam komunikasinya dan terus-terang serta terbuka dalam mengutarakan pikirannya, biasanya bereaksi dengan cara yang sama, terus-terang, dan terbuka. Sebaliknya, bila kita merasa seseorang menyembunyikan perasaannya yang sebenarnya bahwa dia mempunyai rencana atau strategi tersembunyi kita bereaksi secara defensif.Karena itu perlu bersikap profesional artinya bersikap tentative dan berpikiran terbuka serta bersedia mendengar pandangan yang berlawanan dan bersedia mengubah posisi jika keadaan mengharuskan hal ini membantu dalam menciptakan suasana mendukung (sportif). Penilaian, tidak spontan, dan tidak berpikiran terbuka akibat tidak adanya sikap positif pada pelaku komunikasi.Hal ini menyebabkan pula kualitas komunikasi tidak efektif dan ditinggalkan.Facebook menyediakan kualitas ini "sikap mendukung" dalam bentul ikon "like" "jempol" atau komentar bersifat mendukung.

\section{Sikap positif}

Kita mengkomunikasikan sikap positif dalam komunikasi interpersonal dengan sedikitnya dua cara: (1) menyatakan sikap positif dan (2) secara positif mendorong orang yang menjadi teman kita berinteraksi. Sikap positif mengacu pada sedikitnya dua aspek dari komunikasi interpersonal.Pertama, komunikasi interpersonal terbina jika orang memiliki sikap positif terhadap diri mereka sendiri. Orang yang merasa negatif terhadap diri sendiri selalu mengkomunikasikan perasaan ini kepada orang lain yang selanjutnya akan mengembangkan perasaan negatif yang sama. Sebaliknya orang yang merasa positif terhadap diri sendiri mengisyaratkan perasaan ini kepada orang lain, yang selanjutnya akan merefleksikan perasaan positif ini. Kedua, perasaan positif untuk situasi komunikasi pada umumnya sangat penting untuk interaksi yang efektif. Tidak ada yang lebih tidak menyenangkan ketimbang berkomunikasi dengan orang yang tidak menikmati interaksi atau tidak bereaksi secara menyenangkan terhadap situasi atau suasana interaksi. Reaksi negatif terhadap situasi ini membuat orang merasa mengganggu dan komunikasi dengan segera akan terputus.

Sikap positif dapat dijelaskan lebih jauh dengan istilah dorongan di mana dorongan ini dipandang sangat penting dalam analisis transaksional dan dalam interaksi antarmanusia secara umum. Perilaku mendorong menghargai keberadaan dan pentingnya orang lain. Perilaku ini berlawanan bertentangan dengan ketidakpedulian.Dorongan positif umumnya berbentuk pujian atau penghargaan dan terdiri atas perilaku yang biasanya kita harapkan, kita nikmati dan kita banggakan.

Dorongan positif ini mendukung intrapribadi kita dan membuat merasa lebih baik.Sebaliknya, dorongan negatif, bersifat menghukum dan menimbulkan kebencian dan pada akhirnya meninggalkan komunikasi interpersonal. Sikap positif sehingga memunculkan dorongan menghargai dan pentingnya orang lain ketika seseorang ada kesadaraan kesetaraan memandang manusia. 


\section{Kesetaraan}

Komunikasi interpersonal akan lebih efektf bila suasananya setara. Artinya harus ada pengakuan masing-masing pihak sama-sama bernilai dan berharga, dan bahwa masing-masing pihak mempunyai sesuatu yang penting untuk disumbangkan. Dalam suatu hubungan interpersonal yang ditandai oleh kesetaraan, ketidaksependapatan dan konflik, lebih dilihat sebagai upaya untuk memahami perbedaan yang pasti ada ketimbang sebagai kesempatan untuk menjatuhkan pihak lain. Kesetaraan tidak mengharuskan kita menerima dan menyetujui begitu saja semua perilaku verbal dan nonverbal pihak lain. Kesetaraan berarti kita menerima pihak lain atu menurut istlah Carl Rogers, kesetaraan meminta kita untuk memberikan "penghargaan positif tak bersyarat" kepada orang lain.

Memposisikan diri lebih tinggi secara sosial, secara psikis (pintar, baik, bijak), atau secara fisik (cantik, tampan) akan mempengaruhi penilaian keseteraan terhadap manusia. Akibatnya muncul sikap tidak menghargai dan meremehkan.Karena itu perlu dibentuk sikap positif dengan kesadaraan kesetaraan sehingga penghargaan positif tak bersyarat dalam diri pelaku antarkomunikasi terbentuk.Ketika ini tidak terbentuk pada masing-masing pelaku komunikasi, tidak bisa mencapai efektifitas komunikasi interpersonal.Facebook menyediakan group-group yang dirasa setara untuk mengefektifkan komunikasi.

\section{PENUTUP}

Keberadaan new media, khususnya Facebook, tidak bisa dipandang sebelah mata oleh humas.Keberadaannya menjadi peluang dalam mengoptimalkan peran dan fungsinya baik di internal maupun ke eksternal (publik). Keberadaan new media mereposisi fungsi humas yang cenderung tertutup, komunikasi satu arah, menjadi harus terbuka dan komunikasi dua arah terhadap publik. Situasi baru ini menuntut humas harus memiliki kompetensi berinteraksi yang tepat pada publik dan juga komunikasi interpersonal yang efektif di media sosial, khususnya Facebook.

Kompetensi humas dalam membangun interaksi dengan pengguna Facebook perlu dikuasai. Hal ini diperlukan untuk melangsungkan strategi komunikasi interpersonal yang efektif. Interaksi yang terus-menerus dengan cara yang tepat dan positif dengan publiknya di Facebook memunculkan keakraban. Keakraban adalah modal untuk melancarkan informasi atau pengaruh humas terhadap isu-isu tertentu agar terterima di publik.

Keakraban, selain dibentuk oleh interaksi, juga sangat ditentukan oleh komunikasi efektif yang diterapkan humas. Humas dalam berkomunikasi interpersonal harus memenuhi kualitas-kualitas umum dalam komunikasi interpersonal yang efektif, yaitu: 1) Keterbukaan (Openess); 2. Empati (Empathy); 3) Dukungan (Supportiveness); 4) Rasa positif (positiveness); 5) Kesetaraan atau kesamaan (Equality). 


\section{DAFTAR PUSTAKA}

Devito, Joseph A. 1997. Komunikasi Antarmanusia. iindonesiakan Agus Maulana. Jakarta, Profesional Books

Effendi, Onong U. 1993.Ilmu, Teori, dan Filsafat Komunikasi. Bandung, Citra Aditiya Bakti

Liliweri, Alo. 1994. Perspektif Teori Komunikasi Interpersonal: Suatu Pendekatan ke Arah Psikologi Sosial Komunikasi. Bandung, Citra Aditiya Bakti

Mulyana, Deddy. 2007. Ilmu Komunikasi: Suatu Pengantar. Bandung, Remaja Rosdakarya

Rakhmat, Jalaluddin. 1996. Psikologi Komunikasi. Bandung, Remaja Rosdakarya
Mahmud, Mohd Zaidi \& Bahiyah Omar. 2013. "Motif Dan Kekerapan Penggunaan Facebook Dalam Kalangan Pelajar Universiti” dalam Jurnal Komunikasi: Malaysian Journal of Communication (Online), Edisi 29(1):35-54. Tersedia di: $w w w . u k m . m y$

Zaleski, Jeff. 1999. Spiritualitas Cyberspace: Bagaimana Teknologi Komputer Mempengaruhi Kehidupan Keberagaman Manusia. Bandung, Mizan

app.thefacesoffacebook.com 